\title{
Assessing Stress among Undergraduate Pharmacy Students in University of Malaya
}

\author{
Sue Hui Sun', Aziz Zoriah² \\ ${ }^{1}$ Pharmacy Department, University Malaya Medical Centre, University of Malaya, Malaysia \\ ${ }^{2}$ Pharmacy Department, Faculty of Medicine, University of Malaya, Malaysia
}

\begin{abstract}
Health care students, particularly pharmacy students, are believed to experience a higher level of stress as compared to their age-matched peers. This cross-sectional study determined the sources and predictors of stress among 273 undergraduate pharmacy students at a Malaysian public university using the Derogatis Stress Profile instrument. The response rate was $100 \%$. Pearson's correlation was used to examine the association between Grade Point Average (GPA) and stress levels. Paired and Independent t-tests as well as ANOVAs were used to compare the mean stress scores on various variables.Our findings showed that these students did not demonstrate significantly higher levels of stress than the general population, even though their perceived stress levels were significantly higher (mean $=53.55 \pm 7.87 ; p<0.001$ ). The most frequently reported stress was related to academic matters. Additionally, there was a weak, statistically significant negative correlation between stress level and GPA ( $r=-0.159, p=0.009)$ indicating that as stress levels increases, students' GPA decreases. Second year students were found to be the most stressed although stress levels were not statistically different among students across the various academic years. Thus, targeted interventions such as redesigning the curricula may be an effective way of alleviating stress to provide a favourable learning environment for pharmacy students.
\end{abstract}

Keywords: Derogatis Stress Profile, perceived stress, pharmacy undergraduates, stress levels, healthcare.

Key Messages: Pharmacy students' perceived stress levels were significantly higher than the general population. The most frequently reported stress was related to academic matters. There was a weak, negative correlation between stress level and grade point average. Curriculum review could be performed to provide a favourable learning environment for pharmacy students.

\section{INTRODUCTION}

Healthcare students are known to experience a higher level of stress than their university peers. ${ }^{1-3}$ The intensity of a pharmacy programme causes stress in students as it is highly demanding and requires their utmost dedication in order to keep pace with learning in the ever-changing healthcare field. ${ }^{4}$

The sources of stress identified amongst university students include academic-related matters, environmental factors and personal events, ${ }^{5,6}$ with academic-related stress being the most frequently reported source of stress. ${ }^{7}$ There is a growing body of evidence showing that stress may lead to devastating effects such as anxiety, depression, and most commonly, a decline in academic performance. ${ }^{8,9}$ Nevertheless, it is important to note that the perception of stress is dependent on one's ability to appraise and cope with stress. ${ }^{6}$

Many studies have examined the sources of stress among medical, dentistry and nursing students. ${ }^{10}$ However, a review of the literature has identified only a few studies that assessed stress among pharmacy students. ${ }^{11}$ Measuring stress is difficult as it is not easy to quantify stress. Various tools have been developed and used to assess stress but no tool has been established specifically to measure stress among pharmacy students. ${ }^{12}$ One instrument, the Derogatis Stress Profile (DSP), measures psychological stress based on an interactional stress theory model, which correlates environ-
Submission Date :29.12.2014 Accepted Date : :17.01.2015

DOI: 10.5530/ijper.49.2.4 Correspondence Address Assoc. Prof. Dr. Zoriah Aziz,

Department of Pharmacy, Faculty of Medicine, University of Malaya, 50603 Kuala Lumpur, Malaysia

Phoneno:+60379674909

E-mail:zoriah@um.edu.my

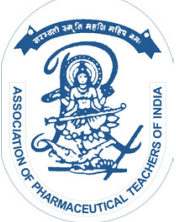

www.ijper.org 
mental events, personality characteristics and emotional responses to stress. ${ }^{13}$ It has been proven to be a valid and reliable tool to measure stress among different populations ${ }^{14}$ including pharmacy students. ${ }^{4}$

Several studies have documented the levels and sources of stress in other healthcare students. ${ }^{1,15}$ One study ${ }^{16}$ which compared the stress level between three groups of healthcare students, namely medical, dental and pharmacy students, found pharmacy students to be the most stressed. Yet, little is known about the prevalence or perceived levels of stress among pharmacy students in Malaysia even though the country has 19 universities offering pharmacy programmes that produce about 1000 pharmacy graduates yearly. Thus, this study aimed to examine stress levels and predictors of stress among pharmacy undergraduate students. In addition, this study explored the correlation between students' academic performance and stress and also differences in stress levels for the same students on two different occasions. We believed the findings of this study would provide a useful foundation for future studies as well as to guide decisions on handling stress among pharmacy students.

\section{METHODS}

\section{Study design}

Undergraduate pharmacy education in all Malaysian public universities is a four-year study programme. All students in the four classes (273 students) in the University of Malaya were invited to complete the questionnaire. The University Medical Research Committee gave approval to conduct this cross-sectional study. Data were collected from all participants on two different occasions 12 weeks apart $\left(\right.$ Time $_{1}$, Time $_{2}$ ), where Time was in the middle of the semester 1 while Time $_{2}$ was at the beginning of semester 2 of the same academic year. One week prior to the first administration of the questionnaire, participants were briefed about the purpose of the study and their consent was obtained. Responses to the self-completed questionnaire were anonymous and confidentiality was strictly maintained.

\section{Instrument}

The survey questionnaire consisted of two sections: the first section collected socio-demographic data, such as ethnicity, current place of stay, students' grade point average (GPA) as well as their sources of stress.

The second section assessed stress with the Derogatis Stress Profile (DSP) instrument. DSP is a validated 77-item self-administered questionnaire measuring psychological stress based on the theory of Lazarus. ${ }^{17}$ This self-report instrument took around 15 minutes to com- plete and individuals were required to rate each item on a 5 -point Likert scale where $0=$ not at all true of me, $1=$ slightly true of me, $2=$ moderately true of me, $3=$ very true of me, and $4=$ extremely true of me. ${ }^{13}$

Consent to use the instrument was obtained from the instrument's developer (Associate Professor Dr. Leonard R. Derogatis) and the questionnaires were purchased from the distributor, Clinical Psychometric Research, United States of America (USA).

\section{Statistical analysis}

Data collected were analyzed with the Statistical Package for Social Sciences (SPSS) version 20.0. Pearson's correlation was used to examine the association between GPA and stress levels. Stress level was assessed by the DSP instrument that provides two total scores: the Total Stress Score (TSS) and the Subjective Stress Score (SSS). ${ }^{17}$ The TSS is a continuous variable that reflects the stress level while SSS "provides an estimate of the respondent's conscious appreciation of his/her current stress level". ${ }^{13}$ For the purpose of this study SSS was referred to as perceived stress score. Paired and Independent t-tests as well as ANOVAs were used to compare the mean stress scores on various variables where appropriate. Multiple regression analysis was conducted to predict factors that influence students' stress level.

\section{RESULTS}

All 273 students completed the questionnaire at twotime points $\left(\right.$ Time $_{1}$ and Time $_{2}$ ). The students mean age was $20.72 \pm 1.26$ and their ages ranged from 19 to 24 years. (Table 1) shows slightly more than three quarters of the respondents were female and half of the students were on a scholarship. The majority of the students walked to classes.

\section{Sources of stress}

Figure 1 shows the percentage of stress from various sources. In the questionnaire students were allowed to indicate more than one source of their stress. The most frequently reported source of stress was related to academic followed by personal life issues, environmental factors and financial issues. The results also showed that $2.2 \%$ of the reported sources of stress was related to other out of class activities such as residential and politics. Sources of stress were similar between Time ${ }_{1}$ and Time .

\section{Students stress level compared to the general population}

One sample t-test conducted to compare the TSS and SSS of the students with the normalized mean of the general population (50 as reported by Derogatis and 
Table 1: Demographic profile of pharmacy students

\begin{tabular}{|c|c|c|}
\hline Variables & \multicolumn{2}{|c|}{ Frequency (\%) } \\
\hline \multicolumn{3}{|l|}{ Gender } \\
\hline Male & 63 & $(23.1)$ \\
\hline Female & 210 & $(76.9)$ \\
\hline \multicolumn{3}{|l|}{ Year of study } \\
\hline First year & 73 & $(26.7)$ \\
\hline Second year & 68 & $(24.9)$ \\
\hline Third year & 70 & $(25.7)$ \\
\hline Fourth year & 62 & $(22.7)$ \\
\hline \multicolumn{3}{|l|}{ Ethnicity } \\
\hline Malay & 133 & (48.7) \\
\hline Chinese & 128 & $(46.9)$ \\
\hline Indian & 6 & $(2.2)$ \\
\hline Others & 6 & $(2.2)$ \\
\hline \multicolumn{3}{|l|}{ Current place of stay } \\
\hline In-campus & 160 & $(58.6)$ \\
\hline Off-campus & 113 & $(41.4)$ \\
\hline \multicolumn{3}{|c|}{ Transport used to come to class } \\
\hline By car & 21 & $(7.7)$ \\
\hline On foot & 230 & $(84.2)$ \\
\hline By public transport & 5 & $(1.8)$ \\
\hline Others & 17 & $(6.2)$ \\
\hline \multicolumn{3}{|l|}{ Financial sources } \\
\hline Loan & 4 & $(1.5)$ \\
\hline Scholarship & 141 & $(51.6)$ \\
\hline Parents & 5 & $(1.8)$ \\
\hline Multiple sources ${ }^{a}$ & 123 & $(45.1)$ \\
\hline \multicolumn{3}{|c|}{ Parents' monthly income ${ }^{b}$} \\
\hline Less than RM 700 & 23 & (8.4) \\
\hline RM 701 - RM 1500 & 72 & $(26.4)$ \\
\hline RM 1501 - RM 5000 & 123 & $(45.1)$ \\
\hline RM 5001 - RM 10000 & 42 & $(15.4)$ \\
\hline More than RM 10000 & 13 & $(4.8)$ \\
\hline
\end{tabular}

Fleming ${ }^{14}$ ) showed that the students' SSS were higher

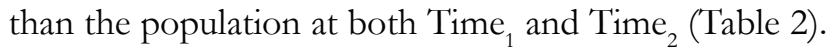
However, only the SSS at Time ${ }_{1}$ was found to be significantly higher $(\mathrm{M}=53.55, \mathrm{SD}=7.87 ; t(272)=7.444, p<$ 0.001). As for TSS, the values at both Time and Time $_{2}$ were significantly lower compared to the population mean.

\section{Changes of stress scores with time}

A paired-samples t-test was conducted to evaluate the changes in stress levels with time. (Table 2) shows that there was a significant decrease in SSS scores from Time ${ }_{1}$ to Time $_{2}(\mathrm{M}=2.79, \mathrm{SD}=9.38, t(272)=4.902, p<$ 0.001). A similar significant decrease was observed for TSS scores $(\mathrm{M}=0.64, \mathrm{SD}=4.26, t(272)=4.147, p<0.001)$ although the reduction was small. There was also a significant difference observed between SSS and TSS at Time $(\mathrm{M}=4.29, \mathrm{SD}=7.39, t(272)=9.592, p<0.001)$ and at Time $_{2}(\mathrm{M}=2.14, \mathrm{SD}=8.53, t(272)=4.147, p<0.001)$.

\section{Association between demographic variables with stress scores}

Independent t-tests were conducted to compare the stress scores for males and females as well as for the variable staying on-campus and off-campus. (Table 3 shows that only SSS at Time for female students was significantly higher than that of male students. At Time ${ }_{1}$ students who lived off-campus showed significantly higher TSS compared to those living on-campus whereas at 'Time $e_{2}$, SSS of students' staying off-campus was significantly higher (Table 3).

Significant differences were observed with the effect

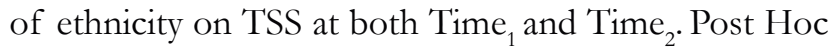
comparisons with Tamhane's T2 tests revealed TSS was significantly higher in Malay students compared to Chinese students.

The ANOVA test revealed that there was no significant relationship between stress scores and classes of study.

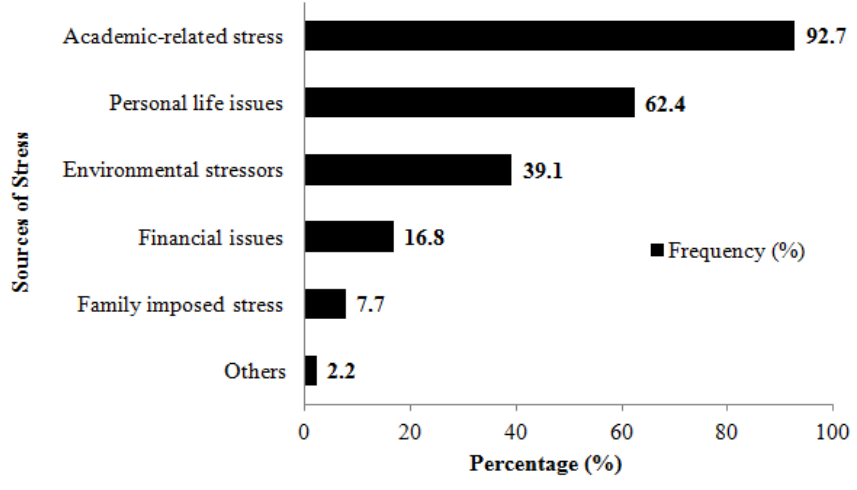

Figure 1: Sources of stress of pharmacy students 
Table 2: Subjective stress score and total stress score for pharmacy students at Time ${ }_{1}$ and Time ${ }_{2}$

\begin{tabular}{|c|c|c|c|}
\hline & Range & Mean (SD) & Median \\
\hline \multicolumn{4}{|l|}{ Time $_{1}$} \\
\hline Subjective Stress Score (SSS) & $36-77$ & $53.55(7.87)^{*}$ & 54 \\
\hline Total Stress Score (TSS) & $20-73$ & $49.26(6.13)^{\star *}$ & 50 \\
\hline \multicolumn{4}{|l|}{ Time $_{2}$} \\
\hline Subjective Stress Score (SSS) & $25-78$ & $50.76(9.09)$ & 51 \\
\hline Total Stress Score (TSS) & $29-67$ & $48.62(6.10)^{*}$ & 50 \\
\hline
\end{tabular}

\begin{tabular}{|c|c|c|c|c|}
\hline & \multicolumn{2}{|c|}{ Time $_{1}$} & \multicolumn{2}{|c|}{ Time $_{2}$} \\
\hline & $\begin{array}{l}\text { Subjective stress score } \\
\text { (SSS) Mean t-scores } \\
\text { (SD) }\end{array}$ & $\begin{array}{l}\text { Total stress score } \\
\text { (TSS) Mean t-scores } \\
\text { (SD) }\end{array}$ & $\begin{array}{c}\text { Subjective stress score } \\
\text { (SSS) Mean t-scores } \\
\text { (SD) }\end{array}$ & $\begin{array}{c}\text { Total stress score } \\
\text { (TSS) Mean t-scores } \\
\text { (SD) }\end{array}$ \\
\hline \multicolumn{5}{|l|}{ Gender } \\
\hline Male & $52.29(8.03)$ & $49.24(6.57)$ & $48.46(8.80)^{*}$ & $48.37(6.57)$ \\
\hline Female & $53.92(7.80)$ & $49.26(6.00)$ & $51.45(9.08)^{*}$ & $48.70(5.97)$ \\
\hline \multicolumn{5}{|l|}{ Year of study } \\
\hline First year & $54.18(7.35)$ & $49.32(6.16)$ & $50.89(9.03)$ & $48.75(6.59)$ \\
\hline Second year & $53.13(8.50)$ & $50.29(5.40)$ & $51.26(9.27)$ & $49.56(5.41)$ \\
\hline Third year & $53.66(8.35)$ & $48.64(7.40)$ & $49.31(9.21)$ & $47.99(6.24)$ \\
\hline Fourth year & $53.13(7.30)$ & $48.74(6.13)$ & $51.69(8.84)$ & $48.16(6.09)$ \\
\hline \multicolumn{5}{|l|}{ Ethnicity } \\
\hline Malay & $53.80(8.41)$ & $50.30(5.41)^{*}$ & $51.23(9.76)$ & $49.79(5.23)^{*}$ \\
\hline Chinese & $53.59(7.40)$ & $48.11(6.82)^{*}$ & $50.34(8.48)$ & $47.48(6.82)^{*}$ \\
\hline Indian & $49.67(7.03)$ & $49.33(4.18)$ & $50.00(9.03)$ & $47.00(6.51)$ \\
\hline Others & $51.00(5.97)$ & $50.50(2.95)$ & $50.33(7.69)$ & $48.83(2.56)$ \\
\hline \multicolumn{5}{|l|}{ Place of residence } \\
\hline In-campus & $52.84(7.28)$ & $48.53(6.33)^{*}$ & $49.83(8.91)^{*}$ & $48.26(6.38)$ \\
\hline Off-campus & $54.55(8.58)$ & $50.28(5.70)^{*}$ & $52.09(9.21)^{*}$ & $49.13(5.68)$ \\
\hline \multicolumn{5}{|c|}{ Transport used to come to class } \\
\hline By car & $51.62(4.47)$ & $50.10(5.50)$ & $51.24(6.60)$ & $48.95(5.55)$ \\
\hline On foot & $53.76(7.99)$ & $49.09(6.22)$ & $50.82(9.25)$ & $49.52(6.17)$ \\
\hline By public transport & $48.60(3.91)$ & $50.60(4.16)$ & $51.80(3.11)$ & $50.60(1.67)$ \\
\hline Others & $54.53(9.84)$ & $50.12(6.31)$ & $49.06(10.97)$ & $49.06(6.87)$ \\
\hline
\end{tabular}
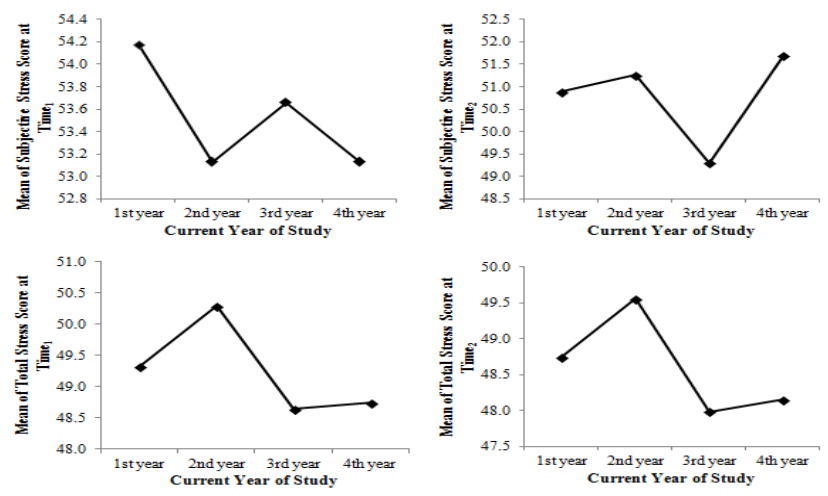

Figure 2: Mean of subjective stress score and total stress score against current year of study at Time ${ }_{1}$ and Time $_{2}$ 


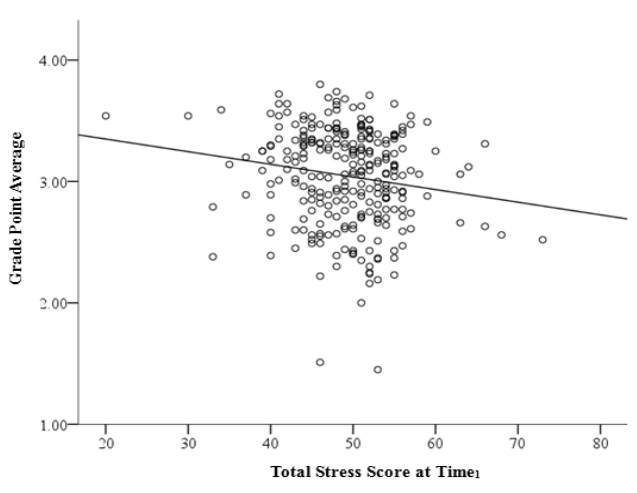

Figure 3: Association between Grade Point Average and Total Stress Score at Time ${ }_{1}$

Even though there was no significant difference between the stress score, Figure 2 shows a consistent pattern for TSS at Time 1 and Time 2 in which TSS increases from the first year to second year and then decreases by the third year of the programme. However, SSS did not show a similar pattern. First year students perceived their stress levels as highest during Time ${ }_{1}$ whereas the fourth year students perceived their stress levels as highest during Time $_{2}$ as seen in Figure 2.

For the other two demographic variables, mode of transport to come to class, and parents' monthly income, no significant differences were found for SSS and TSS at Time ${ }_{1}$ and Time .

\section{Grade point average and total stress score}

Grade point average (GPA) is a measure of student's academic achievement. The GPA of students at Time ranged from 1.45 to 3.80 , with a mean of $3.05 \pm 0.40$. Pearson's correlation test was used to assess the relation-

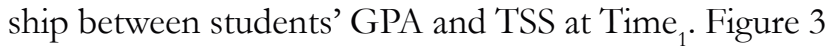
shows that there was a significant weak negative correlation between stress and grade GPA $(r=-0.159, p=0.009)$ indicating that as stress levels increases, students' GPA decreases.

\section{DISCUSSIONS}

The most common source of stress among the pharmacy students was academic-related stress. The findings are in agreement with other studies that examine stress in pharmacy students ${ }^{11}$ and medical students. ${ }^{18}$ The students also frequently reported personal life issues such as inadequate time for rest and recreational activities, lack of time for family and friends, interpersonal conflicts and environmental events as their sources of stress. These findings are similar to those reported by other authors. ${ }^{6,10,19,20}$ This is not surprising as pharmacy training is a rigorous and strenuous endeavour which takes place in a competitive vocational environment.
It is worth noting that various instruments have been used in different studies to assess stress, thus it is difficult to compare stress levels between studies based on the stress scores obtained. As for the stress scores using the DSP, evidence has shown that healthcare students experience higher levels of stress compared to the general population and their peers from other disciplines. ${ }^{21-23}$ Several other DSP studies have shown that, compared to medical and dental students, pharmacy students have higher stress levels. ${ }^{11,16,24}$ When we compared stress levels with another study involving pharmacy students ${ }^{4}$, our students' stress levels were lower whereas they were higher when compared to veterinary students. ${ }^{25}$

The mean total stress scores for our study were significantly lower than the normalized mean of $50 .{ }^{14}$ However, our students' perceived level of stress (SSS) was significantly higher compared to the general population; suggesting that pharmacy students perceive themselves to be more stressful than they actually were.

Our findings also add to the body of evidence that pharmacy students' stress levels differ with time. ${ }^{26,27}$ Many studies addressed the difference in stress levels across academic years but few longitudinal studies examined the variation of stress levels with time. ${ }^{27}$ Students' stress levels were significantly higher during Time ${ }_{1}$ as compared to Time ${ }_{2}$. As Time ${ }_{1}$ was during the period where students needed to complete assignments, laboratory reports and also facing end of semester exams, stress levels were expected to be higher compared to Time, which was at the beginning of a semester. This suggests those students' stress levels were not constant throughout the year but that students experienced higher stress at the time where assignments and examinations are near. ${ }^{28}$ The association between stress and gender in the literature are contradictory. Several studies do not find the relationship ${ }^{1,15}$ while other studies show significant association between the two variables. ${ }^{26,29}$ For example, Fang et $\mathrm{al}^{29}$ suggests that female students are more vulnerable to certain stress and thus more prone to suffer from stress-related depression. This is similar to another study, which involved pharmacy students. ${ }^{4}$ Our results also showed no significant association between stress levels and gender, even though the perceived stress level for females was observed to be higher than males at Time $_{2}$. Therefore, stress level differences between males and females merits further investigation.

Unlike findings from previous studies, ${ }^{10,26,30}$ we did not find a statistically significant difference in stress levels between students from different classes. However, we observed a consistent pattern in which second year students had the highest stress levels at both Time ${ }_{1}$ and Time $_{2}$. This could be attributed to curriculum factors as several studies show that curriculum factors contribute to 
the difference in stress levels across academic classes. ${ }^{26,31}$ In common with findings from previous studies ${ }^{21,32}$ we found the second year curriculum to be crammed, as a lot of basic knowledge has to be imparted in preparation for the transition into the clinical years. Also consistent with other studies ${ }^{33,34}$ our first year students had the highest perceived stress scores during Time $_{1}$ as they were facing the pressure of transition to university and adapting to the new environment.

Malay students had a significantly higher level of stress compared to Chinese students which is in agreement with other Malaysian studies. ${ }^{24,35}$ The difference in stress level could be due to personalities, family background and more importantly the cultural differences between these ethnic groups rather than the stress imposed by the educational environment. In addition, we found that students who lived off-campus had significantly higher stress scores compared to students who lived on-campus. One possible explanation is that students living on-campus usually subscribe to meal plans which are normally cheaper compared to off-campus meals. Additionally off-campus students need to deal with other issues such as relationships with housemates or family members, and other problems related to accommodation. ${ }^{18}$ Studies have shown that students with low socio-economic status and therefore low income have higher stress levels. ${ }^{28,36}$ However, we did not find parents' monthly income to be associated with students' stress levels. This was probably due to the fact that most of the students were on scholarships and thus were able to support their living expenses independent of their parents' monthly income.

Students' GPA is commonly used as an indicator of academic performance. ${ }^{37}$ Previous research on the association of stress with performance has suggested that stress level is inversely correlated with GPA. ${ }^{27,38}$ We found similar results in which higher stress levels in students were associated with lower GPAs. Although a certain amount of stress is necessary to drive better performance, other studies have shown that academic performance may suffer due to high levels of stress. ${ }^{27,39}$ Nevertheless, in agreement with another Malaysian study ${ }^{40}$ we found a weak correlation between stress levels and GPA which could be due to our small sample size. Marshall et $a t^{5}$ on the other hand failed to detect any significant relationship between the two variables. This suggests there is a need for research to investigate the association between stress and academic performance among pharmacy students.

\section{Limitations and strengths of the study}

The findings from this study should be interpreted in the context of several limitations. First, our study population was only from one institution with limited sample size. The findings may not be applicable to student populations from other institutions with different cultures and pharmacy curriculum. Second, the DSP as the instrument of choice in our study is a self-report questionnaire and has not been used to measure stress in our general population. Thus, the validity and reliability of the instrument in the local setting has not been examined. However, the instrument used in our survey has been validated and used in a study which involves pharmacy students. ${ }^{4}$ Finally, the cross-sectional study design only managed to capture the stress levels at two points in time, which is insufficient to address changes in stress over the course of the curriculum.

The strength of this study lies in the fact that there is no bias associated with sampling of the participants as we included all students and the response rate was one hundred per cent. It is also important to note that to our knowledge our study was the first in Malaysia to assess stress among undergraduate pharmacy students using the DSP.

\section{CONCLUSION AND RECOMMENDATIONS}

Healthcare students were commonly believed to experience higher stress compared to their peers from other disciplines and the general population. Although the pharmacy students did not experience significant levels of total stress, their perceived stress levels were significantly higher than the general population. Evidently, stress peaks at distinct times over the course of the year, which justifies a longitudinal, multi-institutional study to assess stress more widely among pharmacy students. Comparative studies of pharmacy students across different institutions would be useful to assess the effects of different curriculum structures on stress levels. Curriculum review may be indicated for the pharmacy programme in this public university.

The results from this study show that the major source of perceived stress in the student population studied was academic. While other variables were related to perceived stress, academic factors are, to a degree, under the control of the University and it may be possible to vary these to the benefit of student stress levels. Further detailed research will be necessary to determine if this is possible and/or desirable.

\section{CONFLICTS OF INTEREST}

There is no conflict of interest to declare for this study.

\section{ACKNOWLEDGEMENT}

We thank all students who took part in the survey and completed the questionnaires. 


\section{REFERENCES}

1. Dyrbye LN, Thomas MR, Shanafelt TD. Systematic review of depression, anxiety, and other indicators of psychological distress among U.S. and Canadian medical students. Acad Med. 2006; 81(4): 354-73.

2. Omigbodun $O O$, Odukogbe AT, Omigbodun AO, Yusuf OB, Bella TT, Olayemi O. Stressors and psychological symptoms in students of medicine and allied health professions in Nigeria. Soc Psychiatry Psychiatr Epidemiol 2006; 41(5): 415-21.

3. Yiu V. Supporting the well-being of medical students. CMAJ. 2005; 172(7): 889-90.

4. Dutta AP, Pyles MA, Miederhaff P. Measuring and understanding stress in pharmacy students. In: Landow MV, editor. Stress and Mental Health of College Students. New York: Nova Science Publishers; 2006. p. 1-28.

5. Doble N, Supriya MV. Student life balance: myth or reality? International Journal of Educational Management 2011; 25(3): 237-51.

6. Marshall LL, Allison A, Nykamp D, Lanke S. Perceived stress and quality of life among doctor of Pharmacy students. Am J Pharm Educ. 2008; 72(6): 137.

7. Harvey L, Drew S, Smith M. The first year experience: A review of literature for the higher education academy. York: The Higher Education Academy; 2006.

8. Dahlin M, Joneborg N, Runeson B. Stress and depression among medical students: A cross-sectional study. Med Educ. 2005; 39(6): 594-604.

9. Misra R, McKean M, West S, Russo T. Academic stress of college students: Comparison of student and faculty perceptions. College Student Journal 2000; 34(2): 236-45.

10. Murphy RJ, Gray SA, Sterling G, Reeves K, DuCette J. A comparative study of professional student stress. J Dent Educ. 2009; 73(3): 328-37.

11. Yusoff MSB, Rahim AFA, Yaacob MJ. Prevalence and sources of stress among Universiti Sains Malaysia medical students. Malays J Med Sci. 2010; 17(1): 30-7.

12. Alzaeem AY, Sulaiman SAS, Gillani SW. Assessment of the validity and reliability for a newly developed Stress in Academic Life Scale (SALS) for pharmacy undergraduates. International Journal of Collaborative Research on Internal Medicine \& Public Health 2010; 2(7): 239-56.

13. Derogatis LR. The Derogatis stress profile (DSP); A summary report. Baltimore, MD: Clinical Psychometric Research; 1995. http://books.google. com.my/books/about/The_Derogatis_Stress_Profile_DSP.html?id=MpT_ tgAACAAJ\&redir_esc=y

14. Derogatis LR, Fleming MP. The Derogatis Stress Profile (DSP): A theorydriven approach to stress measurement. In: Zalaquett CP, Wood RJ, editor. Evaluating stress: a book of resources. London: Scarecrow Press; 1997. p. 113-140.

15. Niemi PM, Vainiomaki PT. Medical students' distress-quality, continuity and gender differences during a six-year medical programme. Med Teach. 2006; 28(2): 136-41.

16. Henning K, Ey S, Shaw D. Perfectionism, the imposter phenomenon and psychological adjustment in medical, dental, nursing and pharmacy students. Med Educ 1998; 32(5): 456-64.

17. Derogatis LR. Synopsis of the Derogatis Stress Profile (DSP®). [Internet]. 1980 [cited 2011 November 12]. Available from http://www.derogatis-tests. com/dsp_synopsis.asp.

18. Alzahem AM, van der Molen HT, Alaujan AH, Schmidt HG, Zamakhshary MH. Stress amongst dental students: a systematic review. Eur J Dent Educ. 2011; 15(1): 8-18.

19. Divaris K, Barlow PJ, Chendea SA, Cheong WS, Dounis A, Dragan IF, et al. The academic environment: the students' perspective. Eur J Dent Educ. 2008; 12(s1): 120-30.
20. Ko SM, Kua EH, Fones CS. Stress and the undergraduates. Singapore Med J. 1999; 40(10): 627-30.

21. Hirsch JD, Do AH, Hollenbach KA, Manoguerra AS, Adler DS. Students' health-related quality of life across the preclinical pharmacy curriculum. Am J of Pharm Educ. 2009; 73(8): 1-6.

22. Leahy CM, Peterson RF, Wilson IG, Newbury JW, Tonkin AL, Turnbull D. Distress levels and self-reported treatment rates for medicine, law, psychology and mechanical engineering tertiary students: cross-sectional study. Aust N Z J Psychiatry. 2010; 44(7): 608-15.

23. Robotham $D$. Stress among higher education students: towards a research agenda. Higher Education 2008; 56(6): 735-46.

24. Johari $A B$, Noor Hassim I. Stress and coping strategies among medical students in National University of Malaysia, Malaysia University of Sabah and University Kuala Lumpur Royal College of Medicine Perak. J Community Health 2009; 15(2): 106-15.

25. Strand EB, Zaparanick TL, Brace JJ. Quality of life and stress factors for veterinary medical students. J Vet Med Educ. 2005; 32(2): 182-92.

26. Polychronopoulou A, Divaris K. A longitudinal study of Greek dental students' perceived sources of stress. J Dent Educ. 2010; 74(5): 524-30.

27. Silverstein ST, Kritz-Silverstein D. A longitudinal study of stress in first-year dental students. J Dent Educ. 2010; 74(8): 836-48.

28. Yusoff MSB, Liew YY, Ling HW, Tan CS, Loke HM, Lim XB, et al. A study on stress, stressors and coping strategies among Malaysian medical students. International Journal of Students' Research 2011; 1(2): 45-50.

29. Fang DZ, Young CB, Golshan S, Fellows I, Moutier C, Zisook S. Depression in premedical undergraduates:a cross-sectional survey. Prim Care Companion J Clin Psychiatry 2010; 12(6): e1-6.

30. Zaid ZA, Chan SC, Ho JJ. Emotional disorders among medical students in a Malaysian private medical school. Singapore Med J. 2007; 48(10): 895-9.

31. Edwards D, Burnard P, Bennett K, Hebden U. A longitudinal study of stress and self-esteem in student nurses. Nurse Educ Today. 2010; 30(1): 78-84.

32. Godefrooij MB, Diemers AD, Scherpbier AJJA. Students' perceptions about the transition to the clinical phase of a medical curriculum with preclinical patient contacts; a focus group study. BMC Med Educ. 2010; 10(1): 1-9.

33. Abdullah MC, Elias H, Mahyuddin R, Uli J. Adjustment amongst first year students in a Malaysian university. European Journal of Social Sciences 2009; 8(3): 496-505.

34. Dyson R, Renk K. Freshmen adaptation to university life: depressive symptoms, stress, and coping. J Clin Psychol 2006; 62(10): 1231-44.

35. Sidhu JK. Effect of stress on medical students. International e-Journal of Science, Medicine and Education 2007; 1(1): 52-3.

36. Bayram N, Bilgel N. The prevalence and socio-demographic correlations of depression, anxiety and stress among a group of university students. Soc Psychiatry Psychiatr Epidemiol 2008; 43(8): 667-72.

37. Sansgiry SS, Bhosle M, Sail K. Factors that affect academic performance among pharmacy students. Am J Pharm Educ. 2006; 70(5): 104.

38. Zajacova A, Lynch SM, Espenshade TJ. Self-efficacy, stress, and academic success in college. Res High Educ. 2005; 46(6): 677-706.

39. American College Health Association. American College Health Association - National College Health Assessment II: Reference Group Executive Summary Spring 2011. Hanover, MD: American College Health Association; 2011.

40. Elias H, Ping WS, Abdullah MC. Stress and academic achievement among Undergraduate Students in Universiti Putra Malaysia. Procedia Soc Behav Sci. 2011; 29(1): 646-55. 